\title{
Art Appreciation of Yuan Blue and White Porcelain Figure Prunus Vase
}

\author{
Chunji Zhang \\ Sichuan Academy of Fine Arts \\ Chongqing, China \\ Jingdezhen Ceramic Institute \\ Jingdezhen, China
}

\begin{abstract}
Fresh and elegant with long implication blue and white porcelain is a bright pearl in China's porcelain history, due to the small number of masterpieces, it has become the collection which many collectors competing to have. This article through the Art Appreciation of the National Heritage Yuan blue and white porcelain figure prunus vase in Hubei Provincial Museum, analyze its artistic features from figurative means, virtual arts, non-utilitarian emotion and self-confirmation aspects, elaborate its artistic content, deepen people's awareness and understanding to the Yuan blue and white porcelain figure prunus vase.
\end{abstract}

Keywords-Yuan blue and white porcelain figure prunus vase; aesthetics; image; virtual; non-utilitarian; self-confirmation

\section{INTRODUCTION}

Blue and white porcelain was born in Tang Dynasty, matured in Song Dynasty, flourished in Yuan Dynasty. Unlike previous introverted porcelain style, Yuan blue and white has created a new era with its distinct straight and flamboyant features. This article through the Art Appreciation of the National Heritage Yuan blue and white porcelain figure prunus vase in Hubei Provincial Museum, deeply dig its artistic nature, deepen people's awareness and understanding to the Yuan blue and white porcelain figure prunus vase.

\section{THE BRIEF INTRODUCTION OF YUAN BLUE AND WHITE PORCELAIN FIGURE PRUNUS VASE}

Blue and white porcelain got its name for its blue flowers on a white background, also known as blue glaze, a kind of underglaze color porcelain. Underglaze color has different firing method from the Tang three-color overglaze and Song dynasty's porcelain, first drawn pattern of ornamentation on a white glaze with blue pigment, and then covered with a layer of transparent glaze, fired at high temperatures of $1300{ }^{\circ} \mathrm{C}$, different shades blue pigment under the transparent underglaze film showing a distinct, crystal clear, bright colors and other characteristics. Blue and white porcelain innovatively use color painting techniques, it is fresh and elegant with long implication and Chinese ink-like charm, blue and white porcelain opened a new era for bisque transit to faience. Among them, especially the Yuan Dynasty blue and white were the most outstanding pieces, in Yuan Dynasty blue and white porcelain firing techniques increasingly matured, the texture is smooth and fine, art work is excellent, themes are rich, styles are diverse, flowers, insects, fish, animals, myths and legends, folk stories, poetry and so all become the painting theme, it is beautifully produced with rare amount handed down so it is very precious.

In 2006, Hubei Zhongxiang Zhengjing Wang tomb unearthed national treasure porcelain, which is Yuan blue and white porcelain figure prunus vase, the vase made by Jiangxi Jingdezhen, and showed the exquisite porcelain firing techniques at that time. The entire piece is exquisitely elegant and refined, especially the chat drawn on the vase is very unique, full of rich cultural atmosphere, it can be called the boutique of Yuan Dynasty blue and white porcelain. The entire appliance dignified and elegant, matrix is heavy and rustic, glaze color is pure, green pigment is intense and bright, the chart theme is unique with rigorous composition and fine painting work, figures are outstanding, showing the perfect firing consummate skill.

This Yuan blue and white porcelain figure prunus vase, four pictures harmony and unity, broke the pattern of one vase one picture, showed the craftsman's bold ideas and innovative conception. This Yuan blue and white porcelain figure prunus vase has a height of $37.6 \mathrm{~cm}$, mouth diameter is $6.2 \mathrm{~cm}$, bottom diameter is $13 \mathrm{~cm}$, narrow mouth, short-necked, plump shoulder, big belly, flat feet, because of its small mouth only can insert prunus so it called prunus vase. Blue and white decoration patterns are all over the vase body, the patterns could divided into upper, middle and lower three layers with curly grass pattern and weigela patterns for the boundary line, the upper layer drawn with phoenix flying picture, the middle layer are four Begonia-shaped openings, separately drawed "Wang Xizhi love orchid picture "," Zhou Dunyi love lotus picture "," Tao Yuanming love chrysanthemum picture ", "Lin Hejing love plum and crane picture" four character patterns, the lower layer drawn with lotus pattern and clouds pattern. The characters on the vase look differently with varied shapes, pattern themes blended with blue and white color and complement each other. 


\section{ART APPRECIATION OF YUAN BLUE AND WHITE PORCELAIN FIGURE PRUNUS VASE}

\section{A. Figurative Method}

Yuan blue and white porcelain figure prunus vase has lifelike characters with sleek, smooth lines, beautiful colors, fine workmanship, perfectly blend with the theme and the blue and white pattern.

In the "Wang Xizhi love orchid picture", Wang Xizhi sit cross-legged in the courtyard, wears a plain gown, the gown is open, expose the shoulders, chest and fubsy belly, showing his rounded sturdy body. Wang Xizhi raised his left hand, index finger pointing to flowering orchid in the front pots, his mouth slightly open, seems like he is reciting poems to appreciate and praise orchids. Orchid placed in a three-legged pot with petal decorations, and the pot is placed on an upper wide lower narrow, top flat stone, so it makes Orchid and Wang Xizhi's sight line at the same level. Near Wang Xizhi's left leg there is a large circular jar, at the mouth of the jar there is a cloud-like spoon handle, behind him there is a book nunnery dressed in a robe holding a book. In the courtyard there are trees with large branches and leaves like plane tree, at the bottom of the stone and the patio both covered with a few bundles of grass. Therefore, "Wang Xizhi love orchid picture" showed the Yuan blue and white porcelain style through fullness of character modeling.

In the "Tao Yuanming love chrysanthemum picture", Tao Yuanming stand in the courtyard, wears wide-sleeved round collar color robe at outside, peach collar shirt inside, tied at the waist with a long waistband, long pants reach his feet, his left hand hang down, right hand holding a long rod with spiral head, his hair tied into a bouquet-like with hair stick, looking back at chrysanthemum. Chrysanthemum inserted in a white vase with small mouth and big belly and held by a page boy with his two hands in the chest, the page boy dressed in plain surplice long robe, tied at the waist with a long waistband, towel fluttering in front of his chest, on his head tied two small buns. Behind Tao Yuanming there is a willow, behind the page boy there is a rockery, on the ground there is grass and flowers, as well as a fungus, these scenes have shown that people stand in the courtyard. "Tao Yuanming love chrysanthemum picture" showed figures dress details in delicate way to reflect the superb painting skills of Yuan Dynasty craftsmen.

In "Zhou Dunyi love lotus picture", Zhou Dunyi wears a crown cap, wears wide-sleeved open type plain breasted robe outside, a white surplice shirt inside, his right hand holding a whisk, standing on the shore, concentrating to enjoy the full bloom Lotus in pond. There are two lotuses in the pond, one has a bloom, another one's bud just ready to burst, the thin dough-shape lotus leaf spread on the water surface, or stand in the water in roll-shape, dotted with waterweeds, the flowerfilled pond with luxuriant foliage shows the thriving scene. Behind Zhou Dunyi there stand a page boy with color robe ,page boy's right arm tucked a rectangular xylophone, closely followed behind his master, which indicate his master will play the xylophone and appreciate the lotus by the pond. The willow behind page boy blocked the sun or his master, there is no rockery, in the courtyard which indicate the figures are in the fields.

In the "Lin Hejing love plum and crane picture", Lin Hejing wears a color surplice robe and a round hat, sitting on a huge rock, in his right hand hold a walking stick with spiral head, his left leg semi-bent toward the ground, and right leg entrenched on the rock, staring at a dancing crane in front of him, overhead is plum in blossom. The dancing crane has graceful posture and clear feather, some of the plum in blossom, some plum's bud just ready to burst, near the foot of the crane there are some rocks and on the ground there are some flower and grass, there are rockeries on both sides of Lin Hejing which indicate he is appreciating plum and crane in the courtyard.

\section{B. The Virtual Art World}

Yuan blue and white porcelain figure prunus vase shows a visual world by the unique porcelain means and also it shows a virtual world. The craftsmen according to the story of the four gentlemen story, through their own imagination, drawn four beautiful pictures, so that the real story has got the artistic process and creation, sublimated into the virtual art world. Combination of virtual and reality, allow the viewers be able to find the reality prototype in the virtual art world, it is good for them to understand the themes and deepen the perception to art work connotation.

The story of Wang Xizhi love the orchid is because when he study calligraphy, he was inspired by the orchid, he put the elegant of orchid, clean, graceful, smooth, and a variety of orchid leaf gestures into his calligraphy, which made his calligraphy got improvement in structure, strokes, and other more sophisticated tricks, gradually formed a unique style of calligraphy. His calligraphy has beautiful font, smooth strokes, it is in sequence and with reasonable density. People see his calligraphy is like to see him in person which indicates his rareness noble quality.

Popular verse "Caiju donglixia, Youran jiannanshan" is the most realistic portrayal of Tao Yuanming love the chrysanthemum. Tao Yuanming enter his official career when he was 29 years old, he has been doing small officer like Jijiu and Canjun, not only he couldn't achieve his great ambition to serve the country, but also he was often forced dealing with officialdom villain who sustained their shame. Later, Tao Yuanming decided to resign and returned back to countryside, no longer involved in the bureaucratic intrigues. Tao Yuanming gave up his career and back to countryside, only wine and chrysanthemum with him, his world known creation "Tao hua yuan ji", is the appreciation for his noble quality.

Zhou Dunyi, Song Dynasty famous thinker, philosopher, litterateur, science originator. Zhou Dunyi was an honest, open mind person, he did not believe in fame, did not afraid of powerful people, and in his whole life he was indifferent to fame and fortune, his noble quality was appreciated by the later generations. His masterpiece "Ai lian shuo" was the best example to reflect his noble quality and free and easy mind. The verse "Chu yuni erburan, zhuo qinglian erbuyao" of the poem, use strong ink to depict lotus's tolerance, integrity, entrusted the author's hope to become a gentleman who was 
proud like the lotus, with the indifferent to fame and fortune and abstinence noble character. Lin Hejing as a hermit, never enter the official career in his whole life and never got married, he lived his life with plum and crane, later he was called plum wife and crane son which become an eternal story.

Lin Hejing's plum poem "Shan yuan xiao mei" in the "Shu ying heng xie shui qing qian, an xiang fu dong yue huang hun", it depicts the deepest winter, plum defying cold, proud and open which brought vitality to the monotonous silence winter, not only made the poet overjoyed, also attracted the crane arrive and dance. Lin Hejing loved deeply for the plum and crane, he lived with plum and crane and far away from the chaos earth, it can be said that plum and crane has penetrated into him and become part of his body, it was the incarnation of his indifferent of fame and fortune and his noble sentiments.

\section{Non-utilitarian Emotions}

The four gentlemen in the four pictures all abandoned high position and handsome salary which ordinary people aspired they showed indifferent to fame and fortune and elegant minded quality, also showed not seeking utility and return to nature sentiment. The noble quality of the four gentleman is difficult for ordinary people to achieve, but they could followed the attitude of giving up worldly utilitarian and enhance self-sentiment and character. Four pictures by means of art to show the non-utilitarian emotions which play a role of moral education. It through paintings to tell people what should follow and what should be avoided, in order to help people form the correct ethics. Ethics is the most basic norms and behavior standard that a person who living in society must comply with, it is a indispensable part of social life. By means of art to transfer the hollow moral ethics into non-utilitarian emotions, deepen the aesthetic content of the work, make the viewers feel the moral education in the appreciation process.

\section{Self-confirmation}

Yuan blue and white porcelain figure prunus vase through porcelain painting art to express people's yearning for the celebrities indifferent to fame and fortune, and their quiet and elegant character, so the viewers could get aesthetic self identity while they confirming their moral characters. When viewers appreciate the four pictures, they got a self verification echo with the characters, and then they accessed the sense of belonging and identity. Viewers found his spiritual home through art, it is a confirmation of the creators' creative ability, and also a confirmation of their own emotional competence. Art appreciation must through mutual recognition and resonance of both creators and viewers, thus the viewers could truly understand the creator's intentions and the meaning of work, in order to achieve the purpose of art aesthetic.

\section{CONCLUSION}

Yuan blue and white porcelain figure prunus vase as a national treasure, through the skillful paintings and ceramics firing techniques to reproduce the scenes of "Wang Xizhi love orchid picture", "Zhou Dunyi love lotus picture", "Tao Yuanming love chrysanthemum picture", "Lin Hejing love plum and crane picture", showed four celebrities' noble quality of indifferent to fame and fortune, and longing for the nature. By means of visualization, virtual art world and non-utilitarian emotions, it shows the noble quality of four gentlemen. Through the viewer's own emotional self-confirmation, it achieves the purpose of art aesthetic.

\section{REFERENCES}

[1] Li Yawen. Analysis about the artistic nature through Yuan blue and white porcelain figure prunus vase [J]. Art Science and Technology, 2014 (4).

[2] Liu Zongbao. Nature of art: First exploration of Yuan blue and white porcelain figure prunus vase [J] Intellect, 2013 (32).

[3] Gao Yulong. Talk about the purpose of art from Yuan blue and white porcelain figure prunus vase[J] Beauty and the times: China 2015 (1).

[4] Liu Mingyu. Analysis about humanistic and ecological characteristics of ceramic art and design with the example of Yuan blue and white porcelain figure prunus vase [J]. Art Education Research, 2013 (10).

[5] Yuan Wenqing.Talk about the four pictures in Yuan blue and white porcelain figure prunus vase [J]. Collectors, 2007 (9).

[6] Li Zhengzheng, Su Xiao. From Yuan blue and white porcelain figure prunus vase to explore the nature of art [J]. Art-life Wenhai Yiyuan, 2012 (9). 